\title{
La migración asiática en el virreinato de la Nueva España: un proceso de globalización (1565-170o)
}

Daniel Méndez Encarnación

Centro de Investigaciones y Estudios Superiores

en Antropología Social, Unidad Peninsular, México

d.mendez@ciesas.edu.mx

Déborah Oropeza, La migración asiática en el virreinato de la Nueva España: un proceso de globalización (1565-1700), México, El Colegio de México, 2020, 375 pp. ISBN 978-607-564-167-6

En este libro, Déborah Oropeza expone, de manera puntual, los resultados de un proceso de investigación riguroso, en torno al fenómeno de la migración asiática ocurrida a través del Pacífico, y sus efectos en la organización de la Nueva España — a nivel político, económico, social y cultural—, desde la segunda mitad del siglo XVI, hasta principios del siglo XVIII. Para quien esté familiarizado con los artículos publicados previamente por la autora — como aquellos de los años 2011 o 2016-, podrá identificar que, algunos asuntos como las características y las condiciones en las que se desarrollaron la migración asiática esclava, y la migración asiática libre, en el territorio novohispano, nuevamente son consideradas como el eje principal desde el cual se estructura este libro.

Lo anterior, no demerita la profundidad y la claridad con que estos problemas históricos son analizados, y ahora, entrelazados - mediante la pulcra narrativa que presenta Oropeza-, con otros elementos igual de importantes, como resultan: la formación de una identidad asiática en el virreinato (que descubre, es común y ambigua, para los diferentes grupos de asiáticos que ingresaron al territorio), la constitución de una sociedad global novohispana, o bien, de la emergencia del (c) (1) (8)

4.0 Internacional 
comercio transpacífico, como un fenómeno articulador y estructurante de dos regiones que, pese a estar distanciadas geográficamente, exhibían rasgos políticoeconómicos y socioculturales compartidos para la época, como fueron Filipinas y la Nueva España.

Mediante una revisión historiográfica crítica sobre el tema de la migración asiática - que repasa a autores como Tatiana Seijas, Thomas Calvo y Jonathan Israel, entre otros-, así como del análisis de datos obtenidos en diversas fuentes primarias, como crónicas, la legislación aplicable del siglo XVI y XVII a los grupos de "chinos", de cuentas de la Caja de Real Hacienda de Acapulco, de informes de obispos, de censos poblacionales, de la correspondencia establecida entre autoridades novohispanas, e inventarios de bienes personales - recuperados de repositorios de orden internacional, nacional y local, como el Archivo General de Indias, el Archivo General de la Nación, el Archivo Histórico de Hacienda, el Archivo General de Notarías de la ciudad de México, la Library of Congress, y más-, la autora demuestra su capacidad de análisis, de síntesis e interpretación, para construir una investigación que, sin duda, es una referencia obligada para los estudiosos de la época colonial en América.

Aunque el texto de Oropeza no es propiamente un estudio comparativo, sí es posible localizar diferentes menciones sobre cómo fue la experiencia de la migración asiática en numerosos puntos del virreinato; es decir, en un espacio que consideró a Filipinas y a la Nueva España, como integrantes de un mismo sistema regional. De esta manera, su principal interés radica en destacar la manera en que, la presencia de un grupo de asiáticos libres y esclavos (tanto en la costa del Pacífico asiático y el americano, como en la ciudad de México), caracterizada por su diversidad étnica - y por tanto, cultural—, favoreció el desarrollo económico en el virreinato, mantuvo vigente el sistema de intercambio mercantil —efectuado a través de la Nao de China, que contó con la participación activa de los asiáticos en los galeones y en los puertos-, transformó las relaciones sociales para la producción de bienes y servicios, e impulsó la integración y adaptación paulatina, de rasgos culturales de los "chinos" a los diferentes sectores de la sociedad novohispana. 
Oropeza, partiendo en el capítulo uno, de un estudio sobre la organización social de Filipinas, así como del fenómeno de la esclavitud y la colonización desarrollada en dicho espacio tras la conquista española y, en el capítulo dos, del problema que representó para la Corona, a mediados del siglo XVI, la búsqueda de una ruta transpacífica —que comunicó de manera regular los territorios de Filipinas y de Nueva España, a través de los puertos de Cavite y Acapulco, respectivamente-, analiza la forma en que se produjeron y se regularon tanto los flujos de intercambio comercial, como de migración asiática esclava y libre, en el periodo que va de 1565 a 1700. Desde este momento, la autora llama la atención sobre un asunto que estará presente a lo largo de su trabajo, es decir, la aplicación genérica que se dio al término "chino" e "indio chino", para registrar e identificar a la población emigrada de Oriente que arribó al territorio de la Nueva España.

La crítica que hace Oropeza, en cuanto al uso indistinto que se hizo de este concepto, por parte de la sociedad novohispana, para referirse a la gente asiática (y que refuta magistralmente, demostrando la heterogeneidad que caracterizó a dicha población), resulta uno de los principales aportes de su obra para la historiografía. Con lo anterior, logra exponer y visibilizar, de manera precisa, los diferentes inconvenientes que representó para la administración española —a nivel jurídico, identitario, religioso, político, económico y social-, el reconocimiento de la masa migrante asiática (libre y esclava) como "indios" o "indios chinos". De la misma manera, ilustra el proceso mediante el cual, se produjo la formación de lo que refiere como una sociedad global al interior del territorio novohispano, impulsada por la movilidad de la población asiática, de su aprovechamiento como mano de obra, así como del consumo generalizado de las mercancías traídas de Manila. Esto, terminó por complejizar a la ya de por sí diversa sociedad de la Nueva España, integrada por españoles, las diferentes castas, indios, negros y ahora, asiáticos.

Por medio de sus hallazgos, en el capítulo tres, expone las causas y los motivos que permitieron llevar a cabo, de manera regular, el flujo migratorio de asiáticos hacia el territorio novohispano. Este proceso estuvo marcado por: el empleo de la ruta transpacífica como un sistema de transporte de mercancías y de personas; en el diseño del modelo de intercambio económico-mercantil establecido entre Filipinas 
y la Nueva España — protagonizado por la Nao de China—; en la participación de los comerciantes, los tripulantes de los galeones, las autoridades reales y las élites españolas para el tráfico de personas; así como las diferentes prácticas subterráneas que tomaron lugar en la organización y la administración de la actividad comercial del Pacífico y de los diferentes puertos marítimos.

Aquí, en contraste con lo ordenado mediante las cédulas reales, y los decretos e informes emitidos por las autoridades novohispanas, el análisis de la autora da a conocer que, la migración esclava fue estimulada en el virreinato, como consecuencia del desarrollo de prácticas ilícitas (incluyendo el soborno a las autoridades, la carga excesiva de mercancías trasladadas en los galeones, o el ingreso al territorio novohispano de esclavos asiáticos, efectuado desde otros puertos marítimos), aunado a la creciente demanda de mano de obra, y a los múltiples beneficios económicos que reportaba, para los tratantes, la venta de esclavos "chinos", tanto en la región del archipiélago filipino, como al interior de la Nueva España.

Tomando en cuenta estos dos fenómenos, - es decir, el trasfondo de una migración considerable de población originaria de Oriente, así como de la expansión del comercio y consumo de mercancías "chinas"-, Oropeza plantea, para los capítulos cuatro y cinco, los procesos de integración efectiva de "chinos" en la región costera del Pacífico del virreinato - principalmente en las alcaldías de Colima, Motines, Zacatula y Acapulco-, así como en la ciudad de México. En ambos espacios, repasa las diferentes actividades que fueron desempeñadas por los asiáticos - destacando entre ellas, la barbería, el cultivo de palma y la producción de cocotero-, y su relación con el estatus jurídico que los determinaba (es decir, libres o esclavos), para clarificar que, la organización del trabajo también respondía a un orden que era socialmente estructurante, diferenciado y jerarquizado. Dadas las características socioeconómicas de ambas regiones, la autora tiene por acierto señalar que, mientras en la costa, la mayor parte de la población asiática era considerada libre, y podía llevar a cabo estrategias para ascender en la escala social - ejemplificado esto, a través de casos muy bien descritos ligados a la actividad comercial desarrollada por los "chinos" y "chinas"-, en la ciudad de México, la población asiática esclava era la que tenía una mayor presencia, siendo retenida 
mediante sistemas de explotación y de arraigo, como en el caso de los obrajes, o del trabajo como servidumbre.

Estas condiciones de la vida cotidiana, a las que fueron expuestos los grupos de asiáticos impulsaron, en ambos casos, el desarrollo de una sociabilidad particular de los "chinos" hacia las instituciones novohispanas, a partir de la proximidad y los vínculos que establecieron con otros grupos poblacionales. Lo anterior, fue expresado a través de prácticas como los matrimonios, la creación de cofradías y de gremios, el establecimiento de compadrazgos y las mayordomías. Gracias a tales estrategias es posible reconocer que, la población de asiáticos analizada en esta obra logró aprovechar la identidad — ambigua y común — creada en torno a la condición jurídica de "indios", con el objetivo de posicionarse en un mejor estrato social, además de crear redes, para poder relacionarse o bien, de distinguirse, de la población de indios naturales.

También, mediante la obtención de derechos y de concesiones, reservados para el sector de población peninsular — como el uso de armas o de caballos, e incluso de su capacidad para participar en la vida comercial, académica y religiosa del virreinato-, los asiáticos libres, demostraron su conocimiento sobre las leyes que fueron establecidas por la propia administración española para su control. Para Oropeza, esto último es un reflejo de la compleja aculturación experimentada por los "chinos" tras su exposición a la cultura iberocristiana, demostrando su integración efectiva a la sociedad de la Nueva España. Finalmente, en el capítulo seis se presentan, de manera breve, algunos de los elementos de la cultura material novohispana, donde puede ser reconocida la influencia asiática. A pesar de que este último asunto, resulta un lugar común para los versados en el tema —al traer a la discusión la creación y el diseño de efectos personales como la vestimenta, los biombos, los muebles, las pinturas, los cocos chocolateros, los cambios ocurridos en la producción de porcelana, las figuras de marfil, el uso de las especias en la gastronomía, o bien, del aprovechamiento de la experiencia asiática para el cultivo de nuevos productos agrícolas y para el desarrollo de la actividad naval—, no deja de ser interesante la manera en cómo se ilustra que, la posesión de productos o mercancías de origen o influencia asiática, sirvió como el mecanismo por excelencia, 
para la distinción por clase o por posición social, de los diferentes grupos que interactuaban en el territorio.

Por último, es necesario destacar que, a lo largo del texto, la selección de la temporalidad abordada está bien justificada, ante las múltiples evidencias de archivo recopiladas por la autora, y que son presentadas de forma diacrónica. Asimismo, el argumento principal sobre la construcción de una sociedad global en la Nueva España, de los siglos XVI a XVIII —donde la presencia de Asia jugó un papel fundamental, expresada en la heterogeneidad poblacional, en las mercancías, las técnicas y las costumbres, que fueron adoptadas por diferentes sectores de la sociedad virreinal-, aporta una perspectiva novedosa para el estudio del fenómeno colonial y migratorio de este periodo.

Sin embargo, nuevas preguntas surgen a la luz de la información proporcionada por Oropeza, por ejemplo ¿̇cuáles fueron las trasformaciones ocurridas en la sociabilidad de los grupos asiáticos, tras la introducción de las Reformas Borbónicas en el territorio novohispano?, o bien, ¿̇cuáles fueron las consecuencias que representó para esta población, el abandono de la ruta transpacífica de la Nao de China?, e incluso ¿qué cambios se produjeron con el fin del boom del consumo de mercancías "chinas" en la Nueva España?, entre muchas otras. Sin lugar a duda, el libro de Oropeza se sumará a la larga lista de trabajos considerados como referentes del estudio histórico de la migración asiática, y que refleja, en este texto, una naturaleza tan compleja que la convierte en un problema necesario de seguirse explorando desde nuevas perspectivas.

\section{Referencias}

Oropeza, D. (2016). La migración asiática libre al centro del virreinato, 1565-1700. Relaciones, 147, 347-363.

Oropeza Keresey, D (2011). La esclavitud asiática en el virreinato de la Nueva España, 1565-1673. Historia Mexicana, LXI(I), 5-57. 